\title{
Echocardiograpic Evaluation of Short-term Outcome of Patent Ductus Arteriosus Closure using Amplatzer Occluder Device
}

Raghda Ghonimy Elsheikh ${ }^{1 *}$, Mohamed Salah Hegab', Mai Mohamed Salama', Mohamed Elsayed Elseteha' and Amany Ibraheem Omar ${ }^{2}$

${ }^{1}$ Cardiology Department, Tanta University; Mahalla Cardiac Center, Tanta, Egypt

${ }^{2}$ Cardiology Department, Faculty of Medicine, Tanta University, Mahalla Cardiac Center \& El-Menshawee Hospital, Tanta, Egypt

\begin{abstract}
Objective: To compare clinical and echocardiographic data before and after transcatheter closure of patent ductusarteriosus (PDA) with occluder device.

Methods: The study population consisted of 30 children with PDA who were subjected to history taking and clinical examination to detect symptoms and signs suggestive of significant shunting. Doppler, two-dimensional echocardiography studies with measurement of mitral inflow velocities in early and late diastole ( $E$ and $A$ wave), early and late diastolic mitral annular velocity (É and Á) by DTI, Tei index, and standard chamber dimensions. All children were studied before and 3 months after percutaneous closure of PDA that done using the Amplatzer device.

Results: Transcatheter closure of PDA produced marked improvement of patients' symptoms and signs postclosure, significant reduction in heart rate and respiratory rate while there was no significant change in blood pressure or temperature. Also there was significant reduction in LV systolic and diastolic dimensions and volumes, LV ejection fraction, left atrial diameter, E wave, A wave, É wave and Á wave while there was significant increase in LV Tei index and no significant change in aortic root diameter, E/A or E/É.
\end{abstract}

Conclusion: Haemodynamic effects of PDA and changes in LV dimensions and function caused by it are reversible after transcatheter closure of PDA.

Keywords: Ductus closure; Pulmonary hypertension; Heart surgery

Abbreviations: DA: Ductus Arteriosus; RV: Right Ventricle; PDA: Patent Ductus Arteriosus; BSA: Body Surface Area; MHz: Megahertz; PW: Pulsed Wave; LV: Left Ventricle; DTI: Doppler Tissue Imaging; SD: Stander deviation; EF: Ejection Fraction; EDD: End Diastolic Dimension; ESD: End Systolic Dimension; LA: Left Atrium; AO: Aorta; EDV: End Diastolic Volume; ESV: End Systolic Volume; FS: Fraction Shortining; TD: Tissue Doppler; ADO: Amplatzer Duct Occluder

\section{Introduction}

In full-term newborns, DA routinely closes within one to five days after delivery, however it's considered abnormal if it remains patent more than three months after birth in term infants [1,2]. The physiological impact and clinical significance of PDA depend largely on its size and the underlying cardiovascular status of the patient, so patients with large PDA may develop left-sided volume overload and pulmonary hypertension at younger ages, leading to diagnosis early in life. If left untreated, PDA can foster the development of infective endarteritis, Eisenmenger syndrome, and other conditions, with an annual mortality rate of $1.8 \%$ [3-5]. Ductus closure is clearly indicated for any child or adult who is symptomatic from significant left-to-right shunting through PDA [3].

Percutaneous closure of PDA has been performed for more than 30 years with several generations of devices and is the preferred mode of therapy worldwide, it has largely replaced surgical ligation in different age groups and become the treatment of choice at many institutions, since it is safe as well as cost-effective and offers considerable advantages over surgical ligation $[6,7]$.

The present study designed to compare clinical and echocardiographic data before and after transcatheter closure of PDA with occluder device.

\section{Patient and Methods}

This study was retrospective case series controlled study. It included 30 patients who were referred to Tanta University hospital with the diagnosis of PDA for comparing the clinical and echocardiographic data before and after transcatheter closure of PDA with occluder device from September 2012 to August 2013. All patients parents gave their written informed consent. Included in the study 8 males $(26.7 \%)$ and 22 females $(72.3 \%)$ with PDA, with a mean age of $5.26 \pm 3.84$ years (range 7 months to 12 years) and with sinus rhythm. The weight of the patients ranged from 7 to $25 \mathrm{Kg}$ with a mean of $16.03 \pm 5.99$, the height of the patients ranged from 40 to $106 \mathrm{~cm}$ with a mean $82.2 \pm$ 22.1, the body surface area (BSA) of the patients ranged from 0.5 to 1.5 with a mean of $0.84 \pm 0.26$. While patients with Coexisting congenital cardiac defects that may need heart surgery, age less than 6 months, body weight less than $6 \mathrm{Kg}$, Irregular rhythm, systemic infections or endocarditis, blood diseases (haemorragic or thrombtic), very large PDA (more than $10 \mathrm{~mm}$ pulmonary end), hypertensive PDA or small restrictive ductus arteriosus (less than $2 \mathrm{~mm}$ pulmonary end with no significant hemodynamic effects) were excluded from the study.

*Corresponding author: Raghda Ghonimy Elsheikh, Professor of Cardiology Tanta University, Tanta, Egypt, Tel: +2 0100130 7271; E-mail: raghdaghonimy@ gmail.com

Received August 05, 2015; Accepted August 27, 2015; Published August 31, 2015

Citation: Elsheikh RG, Hegab MS, Salama MM, Elseteha ME, Omar Al (2015) Echocardiograpic Evaluation of Short-term Outcome of Patent Ductus Arteriosus Closure using Amplatzer Occluder Device. J Cardiovasc Dis Diagn 3: 220. doi: 10.4172/2329-9517.1000220

Copyright: (c) 2015 Elsheikh RG, et al. This is an open-access article distributed under the terms of the Creative Commons Attribution License, which permits unrestricted use, distribution, and reproduction in any medium, provided the original author and source are credited. 
History and clinical examinations were done before and 3 months after PDA closure and data obtained in the two settings were compared.

\section{Echocardiography}

Standard 2-D echocardiogram was performed using Vivid 7 , General Electric Corporation. The echocardiographic examination took place with the patient in the supine position or in left lateral semirecumbence. $5 \mathrm{MHz}$ phased array transducer was used for all patients. It was performed before and three months after percutaneous closure of PDA.

2-D echocardiography was performed to determine the situs, apex position, atrioventricular connections, great vessel relation and abnormalities, ventricular dimensions and functions, state of cardiac valves, venous connections, and any intra cardiac shunts. The quantification of left heart size is important, as it is a surrogate of pulmonary over circulation. M-mode echocardiography was performed to measure the cardiac chamber sizes and quantities left ventricular wall thickness, end systolic and end diastolic diameters and volumes and systolic function. Pulsed Wave Doppler echocardiography: Pulsed-wave (PW) Doppler was performed in the apical 4-chamber view to obtain mitral inflow velocities to assess left ventricle (LV) filling. A multitude of indices such as peak $\mathrm{E}$ and $\mathrm{A}$ velocity, their ratio, and deceleration times were derived from this velocity pattern and proposed as markers for diastolic function. A sample volume was placed between the mitral leaflet tips during diastole to record a crisp velocity profile. Tissue Doppler Echocardiography was performed to measure tissue velocities within LV myocardium \& the tei index. PW Doppler tissue imaging (DTI) was performed in the apical views to acquire mitral annular velocities. The sample volume was positioned at or $1 \mathrm{~cm}$ within the lateral insertion sites of the mitral leaflets and adjusted as necessary (usually $5-10 \mathrm{~mm}$ ) to cover the longitudinal excursion of the mitral annulus in both systole and diastole. The early diastolic (É) waveform occurs during peak ventricular relaxation, the peak late diastolic $(\hat{A})$ waveform represents atrial contraction, these waveforms were derived from tissue Doppler imaging of the lateral mitral annulus then E/ É ratio was obtained to assess diastolic function of LV lateral wall. Tei index was measured by modified method using a built-in software by introducing the time interval from the end to the onset of the left ventricular inflow (a) and the LV ejection time (b) by TDI of the lateral mitral annulus and calculated automatically by the following equation $(a-b) / b$.

The "a" component equals the sum of isovolumic contraction time plus ejection time plus isovolumic relaxation time. The b component is equal to the left ventricular ejection time. The left ventricular tei index was calculated as the difference of a minus $b$ divided by $b$. The left ventricular tei index a component was measured from the trailing edge of the mitral annular Á wave to the leading edge of the subsequent TDI mitral annular early diastolic É wave. The left ventricular tei index $\mathrm{b}$ component was measured from the leading edge to the trailing edge of the TDI mitral annular systolic (S) wave. Four views were used in the study (The high left parasternal long-axis, suprasternal and parasternal short-axis views, the apical 4 chamber view and parasternal long axis view) to diagnose PDA and study the hemodynamic effects of PDA on the heart before closure and to detect changes occurring 3 months after PDA closure.

\section{Cardiac catheterization}

All patients enrolled in the study underwent cardiac catheterization after informed consent, they all were subjected to PDA closure with the Amplatzer duct occluder device under general anesthesia, both arterial and venous access were gained using Seldinger's technique, $50 \mathrm{IU}$ heparin/kg was administered after gaining arterial access. First hemodynamic evaluation was done, then aortogram was done using either NIH or pigtail catheter mostly at the lateral view, if it showed the PDA shape adequately then the measurements were taken. However in some patients the right anterior oblique (RAO) cranial view 35-40 degree was needed for further evaluation of the anatomy of the PDA. Then angiographic measurement of the pulmonary end, the aortic end and the length of the duct were done. A multipurpose catheter was advanced from the venous side into the PDA and placed in the descending aorta. This catheter was exchanged for the delivery sheath over 0.035 exchange wire and the dilator was removed, leaving the sheath in the descending aorta. The delivery cable was passed through the loader and the proper size occlusion device (to be $1-2 \mathrm{~mm}$ larger than the narrowest size of the PDA) was screwed clockwise into the tip of the delivery cable. The device and the loader were immersed in saline solution as the device was pulled into the loader. The loader was introduced into the delivery sheath and without rotation the device was advanced into the descending aorta. The sheath was retracted until the retention disk (the device skirt) was opened in the proximal descending aorta. The sheath with the delivery cable in it was pulled back as one unit until the retention disk was snug against the aortic end of the ampulla. While maintaining tension on the delivery cable, the introducing sheath was withdrawn into the pulmonary artery to deploy the rest of the device into the PDA. With the device still attached to the cable, other aortogram was performed in the lateral projection to confirm device position. When proper device position was confirmed, the device was released by turning the cable counter clockwise using the pin vise. A repeat descending aortogram was performed 10 minutes after the release to assess the degree of residual shunt if present.

\section{Statistics}

Statistical presentation and analysis of the present study was conducted, using the mean \pm , standard deviation (SD) and chi-square test by SPSS V.16. Variables in the patients group pre- and postclosure were compared using Student $t$ test and correlations between LV ejection fraction (EF), transmitral Doppler and tissue Doppler variables were obtained by using multiple regression analysis. $\mathrm{P}<0.05$ is considered significant.

\section{Results}

\section{Clinical data}

Pre-closure 18 patients were symptomatic (60\%), giving history of one or more complains and the rest of patients were asymptomatic (40\%). 4 patients had history of dyspnea (13.3\%), 3 patients had history of feeding difficulties (10\%), 3 patients had history of chest infection (10\%), two patients had history of tachypnea (6.7\%), three patients had history of palpitation (10\%), two patients had history of easy fatigability (6.7\%) and one patient had history of dyspnea and palpitation (3.3\%), (Table 1).

Three months post-closure there was significant improvement $(\mathrm{p}=$ 0.002 ) with only one patient had dyspnea (3.3\%) and the rest of patients had no symptoms (96.7\%).

Clinical examination of the patients before closure of PDA revealed that suprasternal Pulsation presented in 17 patients (56.7\%), PDA murmur presented in 27 patients (90\%), hyper dynamic apex and bound pulse presented in 28 patients $(93.3 \%)$, while 19 patients were pale (amenic) (63.3\%), their Hemoglobin range from $7-9 \mathrm{mg} / \mathrm{dl}$, four 
Page 3 of 6

\begin{tabular}{|c|c|c|c|c|c|c|c|c|c|c|c|c|c|c|c|c|c|}
\hline \multirow[t]{2}{*}{ Symptoms } & \multicolumn{2}{|c|}{ Dyspnea } & \multicolumn{2}{|c|}{$\begin{array}{c}\text { Easy } \\
\text { fatigability }\end{array}$} & \multicolumn{2}{|c|}{ Palpitation } & \multicolumn{2}{|c|}{$\begin{array}{l}\text { Dyspnea + } \\
\text { palpitation }\end{array}$} & \multicolumn{2}{|c|}{$\begin{array}{l}\text { Feeding } \\
\text { difficulties }\end{array}$} & \multicolumn{2}{|c|}{ Chest infection } & \multicolumn{2}{|c|}{ Tachypnea } & \multicolumn{2}{|c|}{ No Complaint } & \multirow{2}{*}{$\begin{array}{c}\text { Total } \\
\mathrm{N}\end{array}$} \\
\hline & $\mathrm{N}$ & $\%$ & $\mathrm{~N}$ & $\%$ & $\mathrm{~N}$ & $\%$ & $\mathrm{~N}$ & $\%$ & $\mathrm{~N}$ & $\%$ & $\mathrm{~N}$ & $\%$ & $\mathrm{~N}$ & $\%$ & $\mathrm{~N}$ & $\%$ & \\
\hline Pre-closure & 4 & 13.3 & 2 & 6.6 & 3 & 10 & 1 & 3.3 & 3 & 10 & 3 & 10 & 2 & 6.7 & 12 & 40 & 30 \\
\hline 3mo post-closure & 1 & 3.3 & 0 & 0 & 0 & 0 & 0 & 0 & 0 & 0 & 0 & 0 & 0 & 0 & 29 & 72.5 & 30 \\
\hline$X^{2}$ & \multicolumn{17}{|c|}{3.336} \\
\hline p. value & & & & & & & & & 0.002 & & & & & & & & \\
\hline
\end{tabular}

Table 1: Symptoms variation in the study population pre- and 3 months post-closure.

\begin{tabular}{|c|c|c|c|c|c|c|c|c|c|}
\hline \multirow[t]{2}{*}{ Signs } & \multicolumn{2}{|c|}{ Suprasternal Pulsation } & \multicolumn{2}{|c|}{ PDA Murmur } & \multicolumn{2}{|c|}{$\begin{array}{l}\text { Hyperdynamic Apex \& } \\
\text { bound pulse }\end{array}$} & \multicolumn{2}{|c|}{ Pallor } & \multirow{2}{*}{$\begin{array}{c}\text { Total } \\
\mathrm{N}\end{array}$} \\
\hline & $N$ & $\%$ & $\mathrm{~N}$ & $\%$ & $\mathrm{~N}$ & $\%$ & $\mathrm{~N}$ & $\%$ & \\
\hline Pre-closure & 17 & 56.7 & 27 & 90 & 28 & 93.3 & 19 & 63.3 & 30 \\
\hline $3 \mathrm{M}$ post-closure & 3 & 10 & 0 & 0 & 0 & 0 & 1 & 3.3 & 30 \\
\hline $\mathbf{X}^{2}$ & \multicolumn{9}{|c|}{3.336} \\
\hline p. value & \multicolumn{9}{|c|}{$0.024^{*}$} \\
\hline
\end{tabular}

Table 2: Signs variation in the study population pre- and 3 months post-closure.

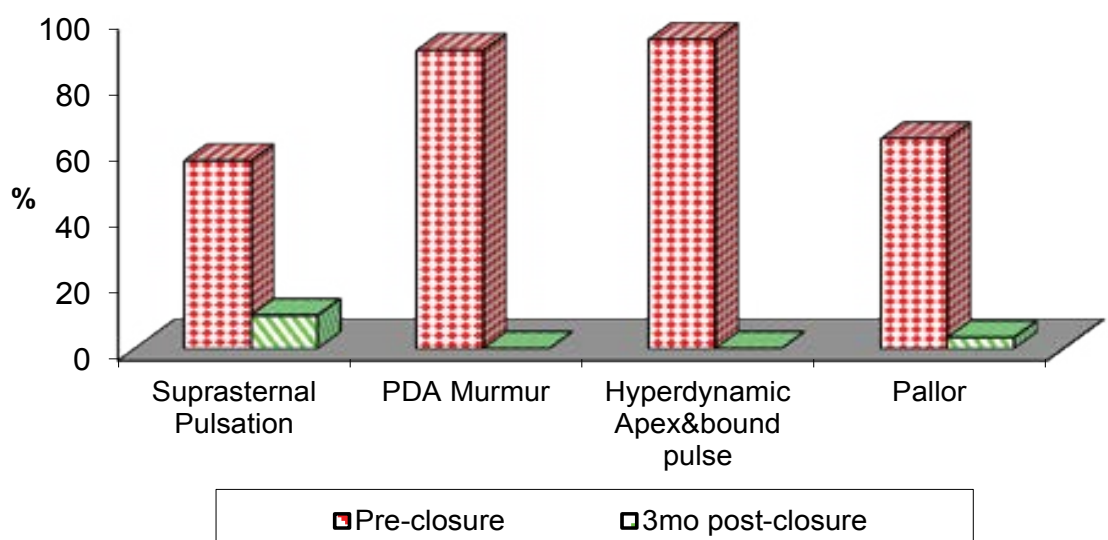

Figure 1: Signs variation in the study population pr- and 3 months post-closure showing significant improvement post-closure.

of them received blood transfusion (backed $\mathrm{RBCs}$ ) and the others were on tonics.

Three months after PDA closure there was significant improvement $(\mathrm{p}=0.024)$ with only three patients had suprasternal Pulsation $(10 \%)$, no patients had PDA murmur (0\%), no patients had hyper dynamic apex and bound pulse ( $0 \%)$, while only one patient had pallor (still anemic and tonics was repeated) (3.3\%), (Table 2), (Figure 1 ).

\section{M mode derived parameters}

A paired sample $\mathrm{T}$ test was used to compare between pre- and postclosure derived M mode echocardiographic data (Figure 2).

The LV end diastolic dimension (EDD) ranged from 20 to $44 \mathrm{~mm}$, with the mean of $33.06 \pm 7.43$ in the pre-closure group, it showed significant reduction $(\mathrm{P}=0.001, \mathrm{r}=0352)$ in the post-closure group as it ranged from 16 to $33 \mathrm{~mm}$ with the mean of $24.84 \pm 5.41$. LV end systolic dimension (ESD) ranged from 15 to $32 \mathrm{~mm}$ with the mean of $21.66 \pm 5.41$ in the pre-closure group , regarding it showed significant decrease $(\mathrm{P}=0.001, \mathrm{r}=0.417)$ in the post-closure group as it ranged from 12.5 to $22 \mathrm{~mm}$ with the mean of $16.83 \pm 3.27$.

Left atrial diameter (LAD) ranged from 16 to 33 with the mean of $24.26 \pm 5.16$ in the pre-closure group, LAD showed significant reduction $(\mathrm{P}=0.001, \mathrm{r}=0.526)$ in the post-closure group as it ranged from 12 to 23 with the mean of $18.53 \pm 3.71$.
Aortic root diameter ranged from 13 to $29 \mathrm{~mm}$ with the mean of $21.2 \pm 4.23$ in the pre-closure group, aortic diameter showed no significant decrease $(\mathrm{P}=0.521, \mathrm{r}=0.475)$ in the post-closure group as it ranged from 12 to $27 \mathrm{~mm}$ with the mean of $20.4 \pm 4.16$.

left atrium (LA) /aorta $(\mathrm{AO})$ ratio ranged from 0.9 to 1.48 with the mean of $1.15 \pm 0.14$ in the pre-closure group, LA/AO ratio showed significant reduction $(\mathrm{P}=0.001, \mathrm{r}=0.426)$ in the post-closure group as it ranged from 0.79 to 1.1 with the mean of $0.91 \pm 0.08$.

LV end diastolic volume (EDV) ranged from 26 to $92 \mathrm{ml}$ with the mean of $55.13 \pm 19.2$ in the pre-closure group, LVEDV showed significant reduction $(\mathrm{P}=0.018, \mathrm{r}=0.526)$ in the post-closure group as it ranged from 22 to $80 \mathrm{ml}$ with the mean of $47.93 \pm 17.40$.

LV end systolic volume (ESV) ranged from 10 to $29 \mathrm{ml}$ with the mean of $18.58 \pm 6.01$ in the pre-closure group, LVESV showed significant reduction $(\mathrm{P}=0.006, \mathrm{r}=0.325)$ in the post-closure group as it ranged from 10 to $26 \mathrm{ml}$ with a mean of $17 \pm 5.44$.

Regarding the LV EF it was ranged from 57 to $79 \%$ with the mean of $66.3 \pm 5.23$ in the pre-closure group, EF showed significant reduction $(\mathrm{P}=0.015, \mathrm{r}=0.302)$ in the post-closure group as it ranged from 55 to $70 \%$ with the mean of $61.8 \pm 5.1$.

The LV fraction shortening (FS)\% ranged from 25 to $45 \%$ with the mean of $35.1 \pm 5.9$, it showed significant reduction $(\mathrm{P}=0.020, \mathrm{r}=0.426)$ 


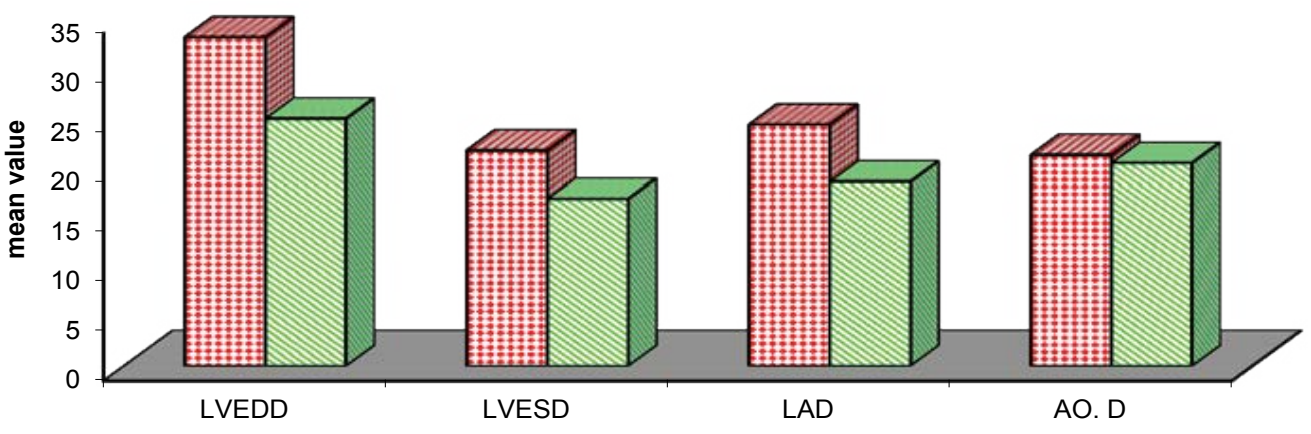

aPre-Closure 口3M. Post-Closure

Figure 2: $\mathrm{M}$ mode echocardiograpic data variation in study population pre- and $3 \mathrm{M}$. post-closure.

\begin{tabular}{|c|c|c|c|c|c|c|c|}
\hline & \multicolumn{2}{|c|}{ Pre-Closure } & \multicolumn{2}{|c|}{ 3M. Post-Closure } & \multirow{2}{*}{ t. test } & \multirow{2}{*}{ p. value } & \multirow{2}{*}{ r value } \\
\hline & Range & Mean \pm SD & Range & Mean \pm SD & & & \\
\hline LVEDD mm & $20-44$ & $33.06 \pm 7.43$ & $16-33$ & $24.86 \pm 5.41$ & 5.631 & $0.001^{*}$ & 0.352 \\
\hline LVESD mm & $15-32$ & $21.66 \pm 5.41$ & $12.5-22$ & $16.83 \pm 3.27$ & 7.529 & $0.001^{*}$ & 0.417 \\
\hline LVEDV ml & $26-92$ & $55.13 \pm 19.2$ & $22-80$ & $44 \pm 17.40$ & 3.336 & $0.018^{*}$ & 0.526 \\
\hline LVESV ml & $10-29$ & $18.58 \pm 6.01$ & $10-26$ & $16.8 \pm 5.44$ & 4.361 & $0.006^{*}$ & 0.325 \\
\hline LAD mm & $16-33$ & $24.26 \pm 5.16$ & $12-23$ & $18.53 \pm 3.71$ & 10.36 & $0.001^{*}$ & 0.526 \\
\hline AO.D mm & $13-29$ & $21.20 \pm 4.23$ & $12-27$ & $20.40 \pm 4.16$ & 1.253 & 0.521 & 0.475 \\
\hline LA/AO & $0.9-1.5$ & $1.15 \pm 0.14$ & $0.79-1.1$ & $0.91 \pm 0.08$ & 6.589 & $0.001^{*}$ & 0.426 \\
\hline EF \% & $57-79$ & $66.3 \pm 5.23$ & $55-70$ & $61.8 \pm 5.1$ & 3.225 & $0.015^{*}$ & 0.302 \\
\hline FS $\%$ & $25-45$ & $35.1 \pm 5.9$ & $23.5-42$ & $32.4 \pm 5.6$ & 3.625 & $0.020^{*}$ & 0.426 \\
\hline $\mathrm{E} \mathrm{cm} / \mathrm{s}$ & $89-110$ & $98.3 \pm 11.8$ & $65-97$ & $85.3 \pm 8.6$ & 9.362 & $0.001^{*}$ & 0.505 \\
\hline $\mathrm{A} \mathrm{cm} / \mathrm{s}$ & $41-83$ & $66.9 \pm 10.4$ & $43-78$ & $60.6 \pm 8.1$ & 3.258 & $0.012^{*}$ & 0.361 \\
\hline$E / A$ & $1.16-2.4$ & $1.47 \pm 0.34$ & $1.12-1.95$ & $1.43 \pm 0.23$ & 0.447 & 0.336 & 0.447 \\
\hline É cm/s & $13-23$ & $17.13 \pm 3.12$ & $12-21$ & $14.86 \pm 2.68$ & 9.335 & $0.004^{*}$ & 0.258 \\
\hline E/É & $3.59-7.4$ & $5.74 \pm 1.13$ & $4.05-7.5$ & $5.89 \pm 1.9$ & 0.562 & 0.818 & 0.299 \\
\hline Tei Index & $0.32-0.44$ & $0.37 \pm 0.03$ & $0.37-0.46$ & $0.40 \pm 0.02$ & 7.593 & $0.001^{*}$ & 0.307 \\
\hline
\end{tabular}

LVEDD: left ventricular end diastolic dimension, LVESD: left ventricular end systolic dimension, LAD: left atrial diameter, AO.D:aortic root diameter, LVEDV: left ventricular end diastolic volume, LVEDV: left ventricular end systolic volume, EF\%: ejection fraction, FS\%: fractional shortening, E vel.: E wave velocity of transmitral flow, A vel.: A wave velocity of transmitral flow, É vel. Lateral: $E$ wave velocity of the lateral mitral annulus, 3M: three months.

Table 3: Echocardiographic Data variation in the study populationpre- and post-closure.

in the post-closure group as it ranged from 23.5 to $42 \%$ with the mean of $32.4 \pm 5.6$.

\section{Echocardigraphic Doppler parameters}

A paired sample $\mathrm{T}$ test was used to compare between pre- and postclosure echocardiographic Doppler parameters (Table 3).

E wave velocity of the transmitral flow ranged from 89 to 110 $\mathrm{cm} / \mathrm{s}$ with the mean of $98.3 \pm 11.8$ in the pre-closure group, it showed significant reduction $(\mathrm{P}=0.001, \mathrm{r}=0.505)$ in the post-closure group as it ranged from 65 to $97 \mathrm{~cm} / \mathrm{s}$ with the mean of $85.3 \pm 8.6$.

A wave velocity of the transmitral flow ranged from 41 to 83 $\mathrm{cm} / \mathrm{s}$ with the mean of $66.9 \pm 10.4$ in the pre-closure group, A wave velocity showed also significant reduction $(\mathrm{P}=0.012, \mathrm{r}=0.361)$ in the post-closure group as it ranged from 43 to $78 \mathrm{~cm} / \mathrm{s}$ with the mean of $60.6 \pm 8.1$. Regarding it to be ranged from 1.16 to 2.4 with the mean of $1.47 \pm 0.34$ in the pre-closure group, E/A ratio showed non-significant reduction $(\mathrm{P}=0.336, \mathrm{r}=0.447)$ in the post-closure group as it ranged from 1.12 to 1.95 with the mean of $1.43 \pm 0.23$

\section{Tissue Doppler (TD) parameters}

A paired sample $\mathrm{T}$ test was used to compare between pre- and postclosure TD parameters. É wave velocity of the lateral mitral annulus ranged from 13 to $23 \mathrm{~cm} / \mathrm{s}$ with the mean of $17.13 \pm 3.12$ in the preclosure group, it showed significant reduction $(\mathrm{P}=0.004, \mathrm{r}=0.258)$ in the post-closure group as it ranged from 12 to $21 \mathrm{~cm} / \mathrm{s}$ with the mean of $14.86 \pm 2$ (Figures 3 and 4 ).

E/É ratio ranged from 3.59 to 7.4 with the mean of $5.74 \pm 1.13$ in the pre-closure group, E/É ratio showed non-significant change $(\mathrm{P}=0.818$, $\mathrm{r}=0.299)$ in the post-closure group as it ranged from 4.05 to 7.5 with the mean of $5.89 \pm 1.9$.

Tei index ranged from 0.32 to 0.44 with the mean of $0.37 \pm 0.03$ in the pre-closure group, Tei index showed significant increase $(\mathrm{P}=0.001$, $\mathrm{r}=0.307$ ) in the post-closure group as it ranged from 0.37 to 0.46 with the mean of $0.4 \pm 0.02$.

There was an excellent positive correlation between the LV EF and FS, É, E velocity and LV Tei index $(r=0.352, p=0.006, r=0.415, p=$ $0.038, \mathrm{r}=0.526, \mathrm{p}=0.020, \mathrm{r}=0.336, \mathrm{p}=0.017$ respectively) (Figure 5). 


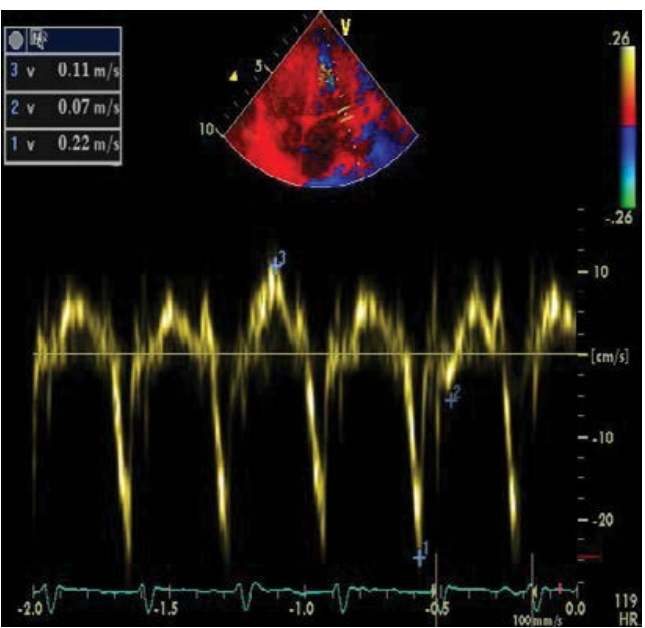

Figure 3: Pulsed DTI of lateral mitral annulus from one of our patient before closure showed É, Á \& S waves.

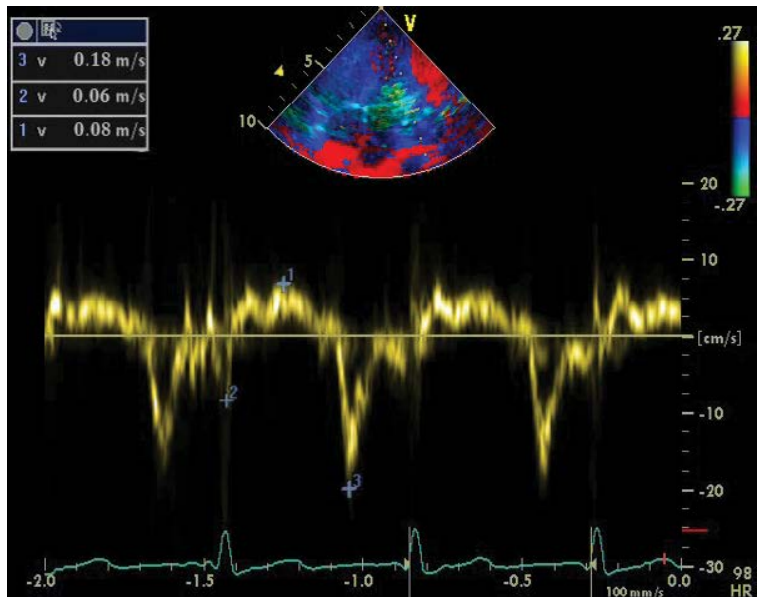

Figure 4: Pulsed DTI of lateral mitral annulus from the same patient 3 months after closure showing significant reduction of É, Á \& S waves.

Angiographic data: Successful closure of PDA was achieved with the use of Amplatzer duct occluder (ADO I) and no complications in all 30 patients. No residual flow in 28 patients with nonsignificant foaming in 2 patients. No recorded vegetations or thrombi in all our patients.
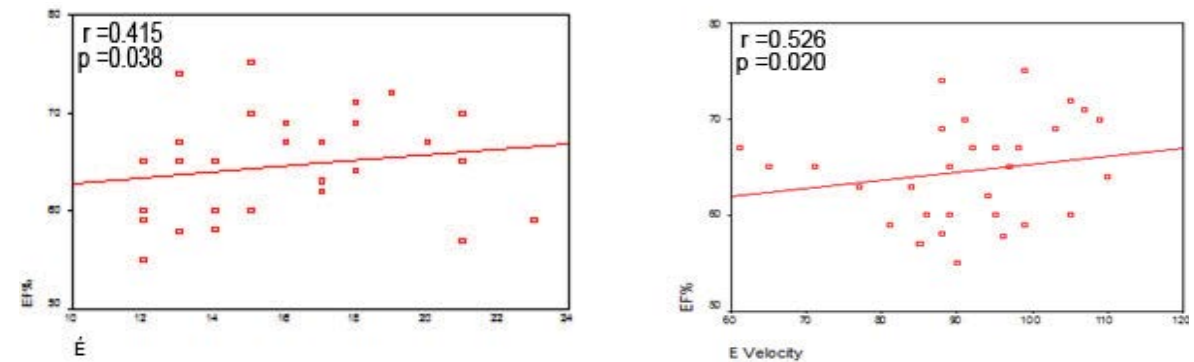

Figure 5: Correlations between ejection fraction and É and $E$ waves velocity.

\section{Discussion}

Interventional closure of the arterial duct has evolved in 1939 when Gross and Hubbard reported the first case closed by surgical ligation through thoracotomy after that various techniques have developed until Porstmann et al. the pioneer of transcatheter occlusion of PDA who reported the first case using a conical Ivalon plug in 1967 since that transcatheter occlusion has become the treatment of choice for most patent ductus in children and adults with the development of techniques and occluders [8-10].

In this study 30 children with patent ductus arteriosus were subjected to transcatheter closure of the duct with Ampatzer duct occluder, complete history, full clinical examination and echocardiographic data were obtained before and 3 months after closure.

All patients had variable symptoms and signs before closure, but there was marked improvement 3 months after closure with only one patient still complaining of exertional dyspnea (grade 1) and one patient had pallor and 3 patients had suprasternal pulsation by clinical examination. All patients included in the study showed significant decrease of heart rate and respiratory rate 3 months post-closure while there was no significant change in blood pressure or temperature.

Similar to our results Gupta et al. [11] reported that all patients with PDA who were subjected to percutaneous closure of the duct showed significant improvement of clinical status, they all were asymptomatic on follow up of more than three months.

Successful closure was achieved in all patients with no residual flow. In 2 patients we had nonsignificant foaming, by angiography and echocardiography on follow up showed no residual shunt.

Reports For patients who undergo transcatheter closure with devices demonstrated that immediate occlusion rates are in excess of $90 \%$ and immediate complication rates are very low [1].

Most patients showed significant decrease in LV diastolic and systolic dimensions, volumes, LV systolic function and fractional shortening.

Left ventricular volume overload is frequently associated with PDA and seems to be required to increase cardiac output by Frank-Starling response through stretching LV muscle fibers, resulting in increased contractility and therefore increased systolic function to overcome significant left-to-right shunt and maintain systemic circulation therefore, because the LV remodeling is caused by significant left-toright shunt through PDA, it is conceivable that $\mathrm{LV}$ reverse remodeling occurs after PDA closure [12]. In accordance with the present study Galal et al. [13] reported that closure of a relatively large PDA results 
in a sudden reduction in LV volume overload, thereby reducing muscle fiber stretch and decreasing systolic function. He hypothesized that changes in after load may be another contributory factor adversely affecting LV systolic performance. Prior to closure, the left ventricle ejects blood both into the high-resistance systemic circulation and via the PDA into the low-resistance pulmonary circulation, while after PDA closure it ejects blood into the high-resistance systemic circulation only. Therefore, we speculate that LV after load increases after closure, which might contribute to the reduced systolic function.

In addition, Eerola et al. [14] reported that: At baseline, in both 2D and $3 \mathrm{D}$ echocardiography, the diastolic and systolic volumes adjusted to body surface area (BSA) were larger in the PDA patients than normal, a difference that disappeared after trancatheter closure, even in the patients with normal sized LVs.

We found that $\mathrm{E}$ wave velocity, A wave velocity of transmitral flow, É wave velocity of lateral mitral annulus showed significant decrease this could be explained by an increase in flow across the mitral valve that disappear after closure with no significant change in E/É.

This diastolic pattern mirrors the pattern of diastolic blood inflow velocities across the atrio-ventricular valves, and early diastolic mitral annular velocity appears to be useful in assessing left ventricular relaxation so the significant reduction in mitral early peak flow velocity, atrial peak flow velocity, might reflect decreased flow through the mitral valve, decreased sympathetic activity, and normalized LV compliance [15]. Also we noticed significant increase in Tei index measured by DTI after closure and our results were in agreement with Cheung et al. [16] who showed that the Tei index is affected significantly by acute changes in loading conditions. Also Lutz et al. [17] stated that an increase in preload decreases the TEI-index indicating its sensitivity to acute increases in left ventricular preload.

\section{Conclusion and Recommendations}

Transcatheter closure of PDA results in marked improvement of clinical and hemodynamic status of the patients. Changes in LV systolic and diastolic indices derived from both conventional echocardiography method and Doppler tissue imaging caused by PDA are reversed three months after percutaneous closure. Even the children with normalsized LV benefit from the procedure.

Percutaneous closure of PDA is a safe and effective procedure achieving high occlusion rate, recommended for all children with small to moderate PDA with nearly no complications.

\section{Limitation}

The limitation of this study was- small numbers of patients were enrolled in the study. Large ducts were excluded while those patients expected to response post closure significantly than smaller size ducts regarding clinical and echocardiography data.

\section{References}

1. Jung JW (2010) Recent strategies and outcomes of transcatheter closure for patent ductus arteriosus. Korean Circ J 40: 216-218.

2. Gentile R, Stevenson G, Dooley T, Franklin D, Kawabori I, et al. (1981) Pulsed Doppler echocardiographic determination of time of ductal closure in normal newborn infants. J Pediatr 98: 443-448.
3. Schneider DJ, Moore JW (2006) Patent ductus arteriosus. Circulation 114: 1873-1882.

4. García-Montes JA, Zabal Cerdeira C, Calderón-Colmenero J, Juanico Enríquez A, Cardona Garza A, et al. (2006) [Patent ductus arteriosus in the adult: transcatheher treatment immediate and medium term results]. Arch Cardiol Mex 76: 163-168.

5. Moore JW, Levi DS, Moore SD, Schneider DJ, Berdjis F (2005) Interventional treatment of patent ductus arteriosus in 2004. Catheter Cardiovasc Interv 64 91-101.

6. Hill SL, Hijazi ZM, Hellenbrand WE, Cheatham JP (2006) Evaluation of the AMPLATZER vascular plug for embolization of peripheral vascular malformations associated with congenital heart disease. Catheter Cardiovasc Interv 67: 113-119.

7. Gupta K, Rao PS (2005) Severe intravascular hemolysis after transcatheter coil occlusion of patent ductus arteriosus. J Invasive Cardiol 17: E15-17.

8. Gross R, Hubbard J (1939) Surgical ligation of a patent ductusarteriosus: a report of first successful case. JAMA 112: $729-731$.

9. Faella HJ, Hijazi ZM (2000) Closure of the patent ductus arteriosus with the amplatzer PDA device: immediate results of the international clinical trial. Catheter Cardiovasc Interv 51: 50-54

10. Thanopoulos BD, Hakim FA, Hiari A, Goussous Y, Basta E, et al. (2000) Further experience with transcatheter closure of the patent ductus arteriosus using the Amplatzer duct occluder. J Am Coll Cardiol 35: 1016-1021.

11. Gupta SK, Krishnamoorthy K, Tharakan JA, Sivasankaran S, Sanjay G, et al. (2011) Percutaneous closure of patent ductus arteriosus in children: Immediate and short-term changes in left ventricular systolic and diastolic function. Ann Pediatr Cardiol 4: 139-144.

12. Takahashi Y, Harada K, Ishida A, Tamura M, Tanaka T, et al. (1996) Changes in left ventricular volume and systolic function before and after the closure of ductus arteriosus in full-term infants. Early Hum Dev 44: 77-85.

13. Galal M, Amin M, Hussein A, Kouatli A, Al-Ata J, et al. (2005) Left ventricular dysfunction after closure of large patent ductusarteriosus. Asian CardiovascThorac Ann 13: 24 -29.

14. Eerola A, Jokinen E, Boldt T and Pinkala J (2006) The Influence of Percutaneous Closure of Patent DuctusArteriosus on Left Ventricular Size and Function A Prospective Study Using Two- and Three-Dimensional Echocardiography and Measurements of Serum Natriuretic Peptides. Journal of the American College of Cardiology 47: 1060-1066.

15. Bruch C, Stypmann J, Gradaus R, Breithardt G, Wichter T (2005) Impact of stroke volume on mitral annular velocities derived from tissue Doppler imaging. Heart 91: 243-244.

16. Cheung M, Smallhorn J, Redington A, and Vogel M (2004) The effects of changes in loading conditions and modulation of inotropic state on the myocardial performance index: comparison with conductance catheter measurements. European Heart Journal 25: 2238-2242.

17. Lutz JT, Giebler R, Peters J (2003) The 'TEl-index' is preload dependent and can be measured by transoesophageal echocardiography during mechanical ventilation. Eur J Anaesthesiol 20: 872-877. 